\title{
Uma leitura arqueogenealógica do racismo estrutural em instituições do sistema de justiça do Maranhão
}

\author{
An archeogenealogical reading of structural racism in Maranhão's justice system \\ institutions \\ Francisco Carlos da SILVA JÚNIOR \\ Mônica da Silva CRUZ \\ Universidade Federal do Maranhão-UFMA \\ http://orcid.org/0000-0002-6811-8107
}

\begin{abstract}
RESUMO: Neste artigo, apoiados no método arqueogenealógico proposto por Michel Foucault (2010), segundo o qual as relações de poder são constitutivas de toda prática (não) discursiva, apresentamos algumas reflexões sobre o racismo estrutural presente em decisões do poder Judiciário do Maranhão, estado onde existe uma das maiores populações negras do país. A pergunta que buscamos responder é: a negação do racismo fomenta o racismo estrutural em redes discursivas da justiça no Maranhão? O corpus se constitui de um processo coletado no Sistema de Justiça do Maranhão (https://jurisconsult.tjma.jus.br/\#/home), processo $\mathrm{n}^{\circ}$ 5911682015, que tramitou na $5^{\circ}$ Vara Criminal do Fórum da Comarca de São Luís. Os resultados demonstram que a negação do racismo pavimenta práticas de impunidade em instituições do sistema de justiça maranhenses
\end{abstract}

PALAVRAS-CHAVE: Racismo Estrutural. Discurso. Acontecimento, Justiça

ABSTRACT: In this paper, supported to archeogenealogical method proposed by Michel Foucault (2010), according to which power relations are constitutive of all (non) discursive practice, we present some reflections on the structural racism present in decisions of the judiciary of Maranhão, state where there is one of the largest black populations in the country. The question we seek to answer is: does denial of racism foster structural racism in discursive justice networks in Maranhão? The corpus is a process collected in the Maranhão justice system (https://jurisconsult.tjma.jus.br/\#/home), process no. 5911682015, which was processed at the 5th criminal court of the São Luís forum. The results demonstrate that the denial of racism paves the way for impunity in institutions of the Maranhão justice system.

KEYWORDS: Structural Racism. Speech. Event. Justice.

\section{Introdução}

Almeida (2018) conceitua racismo estrutural como um conjunto de práticas sociais, econômicas, políticas, institucionais, desenvolvidas por algumas sociedades para privilegiarem certos grupos étnicos em detrimento de outros. Essas práticas estruturam e modelam o modo de ver certos sujeitos e se capilarizam por meio de mecanismos diversos. Como prática estruturante das relações sociais, o racismo estrutural pulverizou-se e normalizou o preconceito em relação a certas etnias em 
diferentes setores, como o econômico, o religioso, o cultural, o político, e até em âmbitos que deveriam proteger as pessoas de toda sorte de discriminação, como a Justiça (SILVA JÚNIOR, 2019).

Neste artigo, apoiados no método arqueogenealógico, proposto por Michel Foucault (2010), apresentamos algumas reflexões sobre o racismo estrutural presente em decisões do poder judiciário do Maranhão, estado onde existe uma das maiores populações negras do país.

Partimos da hipótese de que a negação da existência do racismo, no Brasil, é uma prática que respalda a impunidade do crime de racismo. Dessa observação decorre a problemática deste estudo: a negação do racismo como prática discursiva comum na cultura brasileira reforça a impunidade do crime de racismo? A pesquisa é de natureza qualitativa, documental e se ampara principalmente em estudos bibliográficos. Teoricamente, são mobilizados conceitos propostos por Michel Foucault (2010) sobre a formação e a circulação dos discursos, em suas relações com os poderes. São articulados também estudos referentes ao campo do Direito.

O corpus selecionado se constitui de um processo coletado no sítio de busca do Sistema de Justiça do Maranhão (https://jurisconsult.tjma.jus.br/\#/home), processo $\mathrm{n}^{\mathrm{o}}$ 5911682015, que tramitou na $5^{\circ}$ Vara Criminal do Fórum da Comarca de São Luís. As reflexões aqui desenvolvidas se justificam pela necessidade de pensar uma prática social antiga, o racismo, que ainda circula com grande potência na atualidade, sob diferentes modos.

O trabalho mostra-se relevante pela urgência atual de se descristalizarem certos saberes sobre o povo negro. A ênfase desta discussão incide sobre o papel desempenhado pelo Direito, tendo em vista que o saber jurídico, em perspectiva foucaultiana, é um campo de produção de saberes e poderes que baliza, em grande medida, as relações sociais de um povo.

O texto divide-se em três sessões. Na primeira, apresentamos os conceitos gerais que darão base para a análise do corpus. A segunda se constitui de informações sobre a lei de injúria racial e na terceira sessão apresentamos as análises.

\section{O método arqueogenealógico: uma ferramenta de leitura do racismo estrutural}

O método arqueogenealógico é acionado nesta pesquisa para compreensão das práticas discursivas referentes a situações de discriminação de pessoas negras, no 
âmbito da Justiça do Maranhão, considerando que essas práticas se localizam dentro e fora das instâncias do dizer.

Partimos do entendimento de que o olhar arqueológico associado a uma perspectiva genealógica, voltados para o entendimento das condições de possibilidades de aparição de um discurso, podem explicar as práticas que constituem os processos relativos a delitos de racismo analisados neste estudo.

Desse modo, adotamos o conceito de discurso conforme proposto na Arqueologia, de Michel Foucault (2010), segundo o qual devemos entender o discurso como elemento que institui o saber, o poder, a verdade, o sujeito e a própria realidade.

Como sabemos, a obra de Foucault está dividida em três fases. Na primeira, conhecida como fase arqueológica, a prioridade do autor incide sobre a análise da formação dos saberes. Na segunda fase, genealógica, o foco das pesquisas foucaultianas dirige-se para mecanismos do poder que formam a sociedade, mecanismos que se situam além das ações do Estado. A terceira fase volta-se para discussões sobre a constituição do sujeito ético. Nesta pesquisa, nós nos deteremos em conceitos sinalizados nas duas primeiras fases.

Na fase arqueológica, Foucault (2010) propõe a interpretação do discurso como "fatos" que devem ser entendidos na "estreiteza da sua singularidade", isto é, dentro das condições que lhe permitiram surgir, das regras que lhe autorizaram existir e circular (FOUCAULT, 2010, p.31). Essas regras, para o autor, constituem a episteme de uma época (MUCHAIL, 2004).

$\mathrm{O}$ autor preconiza que o analista observe os aspectos histórico-sociais que margeiam e povoam o discurso. Para isso, é necessário que o discurso seja observado inicialmente em sua dimensão nuclear, isto é, que seja avaliado na forma dos enunciados que o materializam. Cada enunciado, como núcleo do discurso, tem um modo único de existência e de produção de sentidos. Essa síntese delineia as bases de operação do método arqueológico, o qual pode explicar de que modo relações discursivas chancelam o funcionamento da sociedade.

Em perspectiva arqueológica, o analista deve observar quais sujeitos falam no discurso, a quais instituições eles se filiam, qual a articulação dos discursos com a história, sem, contudo, indagar "a" verdade, já que nessa perspectiva a verdade é sempre relativa.

A arqueologia, de Foucault, propõe o estudo das "regras" que regulam os "sistemas" de discursos (GONÇALVES, 2009, p.9) o que exige a leitura do conjunto de 
enunciados que forma o discurso, formação a qual existe apenas dentro de determinados preceitos disponíveis.

Cada época possui um "arquivo", isto é, um agrupamento de discursos efetivamente pronunciados em um momento dado, que funciona segundo condições específicas, e se perpetua historicamente. Fazer análise arqueológica consiste em compreender a "massa documentária" de um dado momento, compreender suas regras, suas práticas, suas possibilidades de funcionamento, entre as quais estão os "limites e formas de dizibilidade", os modos de preservação e de retomada da sua memória. (REVEL, 2005, p.18-19).

Gonçalves (2009) frisa que essas relações se situam no nível mais elementar do discurso (o enunciado) ao nível mais complexo (as formações discursivas). O discurso, arqueologicamente, é entendido como um conjunto de enunciados que se apoiam em uma mesma formação discursiva, chamada adiante FD. Uma FD, como uma das instâncias da cadeia discursiva, é o que determina o que pode e o que deve ser dito pelo sujeito em certas circunstâncias. Nesse âmbito, os enunciados se inscrevem, historicamente, obedecendo a regimes de verdade, que estão dentro e fora da linguagem.

Seguindo esse circuito, podemos dizer que vários enunciados sobre a pessoa negra, ao serem pronunciados dentro de certas formações discursivas, como a FD política, a econômica ou mesmo a científica, construíram, em diferentes momentos, o que entendemos hoje por racismo. Esses enunciados, ao serem executados em algumas regiões, alinham-se a outros dizeres, filiam-se a memórias e a interesses que respaldam formas de o negro ser objetivado. Um exemplo desse mecanismo de produção de sentidos pode ser observado no enunciado "ele é um negro de alma branca", o qual, proferido em dada conjuntura histórica, produz vários sentidos sobre a condição de ser negro. Assim, se em outras épocas esse dizer soava como elogio para alguns, atualmente, sob condições históricas e culturais em que parte da sociedade questiona a desigualdade social, o direito à diferença, momento em que novos regimes de verdade se impõem, surgem formações discursivas que repudiam essa "frase", por suscitar sérias implicações raciais.

O método arqueológico, voltado para explicações sobre a produção dos saberes, envolve mais questões relativas à ordem do dizer, às relações interdiscursivas, de onde são observados sujeitos, relações de poder e produção de práticas. Ao ampliar seus estudos, Foucault dá conta do alcance do discurso em práticas não discursivas, o que lhe exigiu uma ampliação do método arqueológico. O filósofo, então, pensou outras formas 
de instrumentalizar suas análises, considerando a produção do saber pelo poder, chamando essa etapa dos seus estudos de "genealogia".

Muchail (2004) pontua que nesse momento dos escritos de Foucault analisa-se o entrecruzamento das práticas discursivas:

com a trama das instituições e práticas sociais, como faz principalmente em sua história do nascimento das prisões (Vigiar e Punir). Abandona, praticamente, a noção de episteme pela noção mais complexa de dispositivo estratégico, entendendo-se que enquanto a episteme é também um dispositivo - ou antes um elemento prioritariamente discursivo do dispositivo - o dispositivo de natureza estratégica envolve articulações entre elementos heterogêneos, discursivos e extradiscursivos, tais como práticas jurídicas, projetos arquitetônicos, instituições sociais diversas. (MUCHAIL, 2004, p. 15).

Inspirado na perspectiva de poder proposta por Nietzsche, Foucault observa a indissolubilidade entre os discursos e as relações de poder. Nessa fase, o autor nota que a relação discurso, saber e poder liga-se a modos como (só) certos sujeitos estão autorizados, em dada conjuntura, a enunciar certos discursos. Em vista disso, enfatiza questões ligadas a um conceito de poder peculiar e instaura o conceito de "dispositivo", uma instância produtora e ao mesmo tempo controladora de práticas discursivas e/ou não discursivas (MUCHAIL, 2004).

Em síntese, para o campo dos estudos discursivos foucaultianos, analisar discursos consiste em identificar as condições de possibilidade de um discurso aparecer, consiste também em delinear quais são os mecanismos de controle dos discursos, que os delimita conforme táticas e estratégias, definindo como são produzidos e de que forma devem circular.

Conforme Gregolin (2018), uma peculiaridade dos estudos foucaultianos é causar pequenas explosões. Por essa via, o método arqueogenealógico objetiva primordialmente dissolver a noção de que os discursos constituem uma manifestação autônoma dos sujeitos ou instituições e busca compreendê-los como resultantes de uma rede de relações de poder, de engendramento de saberes que os deslocam de qualquer concepção natural.

Esses princípios se alinham às discussões sobre racismo estrutural, na medida em que nos fazem entender que o racismo não é uma prática natural, mas uma criação histórica, estruturada política, econômica e institucionalmente; que os atos racistas se configuram em múltiplos formatos, que eles se manifestam em palavras, em organização espacial, em atitudes, crenças, leis e, portanto, trata-se de uma prática que se estabelece por meio de dispositivos. 
Considerando que a justiça, como um campo do saber, também é atravessada por vários saberes e relações de poder que determinam como o racismo deve ser enfrentado, no próximo item discutimos como a lei da injúria racial, a qual abona práticas de racismo, filia-se arqueologicamente a discursividades anteriores, que constituíram a formação social do país, consolidando práticas culturais que escamoteiam o crime de racismo, no Brasil.

\section{A negação do racismo no Brasil e a lei de injúria racial}

Conforme situamos anteriormente, neste artigo, problematizamos a negação do racismo como mecanismo que fortalece a impunidade do crime de racismo em nossa sociedade, e, para isso, vamos discutir arqueogenealogicamente a pergunta.

A emergência e a circulação do discurso de negação do racismo no âmbito das instituições do sistema de justiça do Maranhão tem uma história de origens tão fortemente diluídas no tempo que não conseguimos captá-las senão fazendo alguns recortes. Nesse sentido, abordaremos brevemente dois acontecimentos discursivos citados por autores que debatem o racismo.

Westin (2020), citando Sílvio Almeida, destaca que no início do século XX dois acontecimentos abalizaram relevantemente a discussão das raízes do racismo estrutural. Um deles é o aparecimento de uma prática que ficou reconhecida como racismo científico, pautada na crença de que o negro seria o motivo das crises da Primeira República, no Brasil. Nesse momento, marcado pelo pensamento eugenista, surgiu o discurso de que a miscigenação seria uma saída para a diminuição das desigualdades sociais que assolavam o país naquele momento. A mistura de sangues de negros e brancos ajudaria a eliminar o negro da sociedade brasileira, pois o sangue branco prevaleceria, já que se mostrava mais forte.

Nos anos 1930, a miscigenação também é avaliada como uma saída para o país formado em bases escravocratas e nessa década irrompe o discurso de um Brasil plural, em que cada povo (indígenas, brancos e negros) ficaria em seu lugar. Nessa estrutura, o negro não seria eliminado, mas mantido em situação subalterna.

Segundo Almeida (2017), a democracia racial é um discurso de extrema potência, mas geralmente é descolado de outra questão relevante, que é a formação social do Brasil, em seu viés econômico e político. O autor pontua que esse discurso ganhou forma no projeto político dos anos 30, momento de criação de um projeto de industrialização do país, que buscava a unificação nacional e ideológica. Esse discurso 
se implanta, então, em um país que já possuía uma população numerosa, caracterizada por uma profunda desigualdade social, não resolvida na Republica Velha. Então, o Estado precisava criar um mercado consumidor e plural, que seria motivado e abrigado no discurso da democracia racial. O discurso da democracia racial se tornou muito forte e penetrou não apenas as práticas populares do cotidiano, mas todas as instituições sociais que formam o Estado, como universidades e instituições, em geral. Além disso, essa discursividade da igualdade entre as raças passou a formar subjetividades, inclusive, subjetividades negras, tornando-se tão sutil que às vezes nem a população negra se dá conta de que está sendo preconceituosa com outros negros. Segundo Almeida (2017), o discurso da democracia racial levou os negros a viverem a condição de negro na sua realidade de miséria, encarceramento e pobreza pois silenciava, sob o manto da harmonia entre as diferenças das raças e classes, as desigualdades sociais.

Esse discurso é extremamente perverso, segundo o autor, porque faz os brasileiros acreditarem que não existe ódio racial aqui, que no Brasil vivemos miscigenados, felizes e sem conflito. Ele foi construído de uma forma tão habilidosa que os brasileiros chegam ao ponto de não quererem ou não conseguirem enxergar a realidade de violência que está diante dos seus olhos. Ainda hoje a discursividade da democracia racial se revela de modo muito vivo em práticas cotidianas do povo brasileiro e serve para naturalizar o racismo no país (WESTIN, 2020).

$\mathrm{O}$ discurso da democracia racial se incorporou em diferenças esferas sociais, e no campo da justiça ele penetrou por ser o Direito atravessado por um conjunto de saberes, o que o desloca da concepção de soberania e de pureza da norma jurídica ${ }^{1}$ situando-o no terreno da historicidade.

Segundo Rocha (2011), na obra de Foucault não existe um delineamento sobre o Direito como campo do saber, mas podemos captar espectros dessa discussão se considerarmos que esse saber é um lugar frequentemente permeado por estratégias de saber e de poder que o condicionam a ser um dispositivo gerador de verdades.

\footnotetext{
1 A concepção da pureza da norma jurídica, desvinculada de todas as influências emanadas da realidade foi formulada por Hans Kelsen (1991), na Teoria Pura do Direito. Esta teoria, que tem grande influência na construção do Positivismo Jurídico, e tem entre seus principais fundamentos um conceito de poder, vinculado à soberania do Estado, promove uma cisão entre o direito e historicidade, ressaltando o Direito Posto, ou direito positivado, surgido a partir das normas jurídicas emanadas do Estado, como a expressão de um saber científico, um saber advindo da ciência jurídica. KELSEN, Hans. Teoria Pura do Direito. Trad. João Baptista Machado. São Paulo: Martins Fontes, 1991.
} 
Uma das grandes conquistas vinculadas à luta antirracismo, desenvolvidas no Brasil, foi a determinação pela Constituição de 1988 para que fosse instituída uma legislação destinada a criminalizar a prática do racismo. Assim é o que estabelece o comando normativo contido na Carta da República no artigo $5^{\circ}$, inciso XLII, cuja redação afirma que "a prática do racismo constitui crime inafiançável e imprescritível, sujeito à pena de reclusão, nos termos da lei”.

Além dessa norma, que criminaliza a prática do racismo, e está situada no artigo $5^{\circ}$ da Constituição, que trata dos Direitos e Garantias Fundamentais, o texto constitucional traz outra norma referente ao racismo. Trata-se do artigo $4^{\circ}$, referente aos princípios que regem a República Federativa do Brasil, nas relações internacionais, o repúdio à prática do racismo.

Atendendo ao comando constitucional em 1989, foi incluída no ordenamento jurídico brasileiro a Lei 7816/89, denominada Lei Caô, que tipificou as condutas consideradas como práticas racistas. A Lei recebeu este nome em homenagem ao autor da proposta, o deputado Carlos Alberto Caô, integrante do movimento negro e participante ativo da Assembleia Nacional Constituinte.

Entretanto, um acontecimento discursivo, vinculado ao campo jurídico, ocorrido oito anos após a entrada em vigor da Lei Caô, incluiu na legislação pátria, o delito de injúria racial. Trata-se da Lei 9.549/97 que suscitou condições para a consolidação de um discurso de negação do racismo no âmbito das instituições do sistema de justiça.

A partir da entrada em vigor dessa lei, as denúncias de práticas de racismo passaram por um processo de classificação, no âmbito das instituições do sistema de justiça, sendo catalogadas como delito de injúria racial, que, ao contrário dos delitos tipificados como práticas de racismo na Lei Caô, recebe uma pena mais branda.

No delito de racismo, a ação penal é pública e incondicionada, e na injúria racial, depende da representação da vítima. Apesar da legislação referente ao delito de injúria racial considerá-lo prescritível, ao contrário do racismo que é, por determinação constitucional, imprescritível e inafiançável, uma decisão do Superior Tribunal de Justiça $(\mathrm{STJ})^{2}$, posteriormente reconhecida também pelo Supremo Tribunal Federal

\footnotetext{
${ }^{2}$ Em julgamento ocorrido no ano de 2015, o Superior Tribunal de Justiça (STJ) decidiu que injúria racial é equivalente à prática de racismo e, portanto, imprescritível. Com esse entendimento, a $6^{\mathrm{a}}$ Turma do STJ restabeleceu a condenação a um ano e oito meses de reclusão por injúria racial que havia sido anulada pela Câmara Criminal do Tribunal de Justiça do Distrito Federal sob o argumento de ocorrência da prescrição. No entanto, seguindo voto do relator do caso, o ministro Ericson Maranho, o STJ concluiu que a injúria racial é imprescritível. Em seu voto, Maranho citou ainda o entendimento do jurista Guilherme de Souza Nucci, segundo o qual, com o advento da Lei 9.459/97, introduzindo a denominada injúria
} 
(STF), considera que o delito de injúria racial é uma prática racista e também deve ser considerada imprescritível.

A produção e circulação de discursos, não apenas nas instituições do sistema de justiça, mas também em outras instituições, são disciplinadas por procedimentos que Foucault (1996) define como procedimentos internos de delimitação e controle destes discursos e que se manifestam "sobretudo a título de princípios de classificação, de ordenação, de distribuição, como se tratasse dessa vez de se submeter a outra dimensão do discurso". (FOUCAULT, 1996, p. 21).

Estes procedimentos internos deixam a critério do saber dos sujeitos que integram as instituições do sistema de justiça a decisão de julgar se um caso concreto é ou não prática de racismo. Dessa maneira, desde o advento da lei que instituiu o delito de injúria racial, "a engenharia jurídica de negação da existência do racismo no Brasil elevou a níveis inimagináveis a violentação de tantos homens e mulheres submetidos a inquéritos conduzidos para “dar em nada”. (ARAÚJO, 2018.p 3).

O discurso de negação do racismo, que circula no âmbito das instituições de justiça do Maranhão, emerge a partir da articulação entre o discurso interno e a ordem dos procedimentos externos de disciplinamento dos discursos. O discurso interno referese à verdade produzida pelo saber jurídico, materializado no uso da técnica de classificação de atos de racismo, como situações de injúria racial. Esse discurso, implantado no seio das instituições do sistema de justiça, liga-se ao discurso da democracia racial, instaurador de uma verdade sobre a convivência harmônica e igualitária das raças, no Brasil.

A negação do racismo surge como elemento presente no cerne da sociedade brasileira, permeada por práticas discursivas e não discursivas que sedimentaram a concepção de que não vivemos em um país onde o racismo não deve ser visto como exceção e sim como regra.

Isto ocorre em razão de todos os acontecimentos discursivos vinculados à formação discursiva do racismo estrutural estarem inscritos no arquivo do racismo. $\mathrm{O}$ arquivo, como dito anteriormente, é uma categoria que, nos estudos foucaultianos do discurso, "faz aparecerem as regras de uma prática que permite aos enunciados

racial, criou-se mais um delito no cenário do racismo, portanto, imprescritível, inafiançável e sujeito à pena de reclusão. Disponível em < https://www.conjur.com.br/2016-out-29/diario-classe-pensaratualidade-teoria-pura-direito-hans-kelsen>. Acesso em 10 de agosto de 2018. 
subsistirem, e ao mesmo tempo se modificarem regularmente. É o sistema geral de formação e transformação dos enunciados (FOUCAULT, 2010, p. 147).

Para visualizarmos a negação do racismo como elemento que promove, no âmbito das instituições do sistema de justiça, o crime de racismo, trazemos a seguir um caso que chegou ao campo da Justiça do Maranhão.

\section{A advogada e os negros que descarregavam uma mudança: "preto é tudo igual, estúpido, burro e não pensa!"}

Manhã do dia 06 de novembro, de 2015, em um dos bairros mais populosos de São Luís, dois homens negros descarregam a mudança de um caminhão, que obstrui a passagem de outros veículos. Uma advogada, irritada com a situação, para o carro que dirige e afirma, no meio da rua: "Preto é tudo igual, estúpido, burro e não pensa". Um dos homens se identifica como policial militar e dá voz de prisão à advogada por crime de racismo.

O caso tem repercussão na mídia, é registrado boletim de ocorrência, mas a autoridade policial não considera que o fato de uma pessoa afirmar, no meio da rua de um dos bairros mais movimentados de São Luís, que burrice e estupidez são características comuns a todos os pretos, configura a prática de racismo e diz que pela situação narrada houve indícios de ocorrência de injúria racial. A mesma posição foi manifestada pelo Ministério Público, que inclusive pediu a suspensão condicional do processo, proposta aceita pela acusada e com isto o caso foi encerrado e arquivado. Essa é a breve síntese do acontecimento discursivo, catalogado no sistema judiciário do Maranhão como processo de $\mathrm{n}^{\circ} 5911682015$, que tramitou na $5^{\circ}$ Vara Criminal do Fórum da Comarca de São Luís ${ }^{3}$.

O metódo arqueogenealógico de análise de discurso, adotado neste trabalho, tem como uma das premissas a conexão entre os acontecimentos discursivos e as relações de poder. Neste caso analisado, também por conta de uma opção metodológica, as pessoas envolvidas na situação são identificadas pela função exercida, pela posição ocupada em uma estrutura social, delimitada racialmente.

Neste acontecimento discursivo, a opção metodológica de usar o termo "negros que descarregavam a mudança" foi adotada considerando-se a atividade braçal, tomada

\footnotetext{
${ }^{3} \mathrm{O}$ material integrante do corpus da pesquisa constitui-se dos autos de três processos que tramitaram no período de dez anos (2008 a 2018), nas Instituições do Sistema de Justiça, processos relacionados a denúncias de práticas racistas, e que, em nosso critério de busca, apresentaram como ponto de convergência a incidência do discurso de negação do racismo.
} 
como menos qualificada, definida no âmbito de uma estrutura social, constituída pelo racismo como a que são reservadas aos negros. Este procedimento de enfatizar a posição ocupada pelos sujeitos integrantes das relações de poder, que permeiam os acontecimentos discursivos objetos dessa análise, é respaldada pela concepção de sujeito definida pela teoria foucaultiana como uma função exercida no enunciado. $\mathrm{O}$ lugar ocupado por este sujeito é uma "dimensão que caracteriza toda formulação enquanto enunciado, constituindo um dos traços que pertence exclusivamente à função enunciativa". (FOUCAULT, 1987, p. 108).

Neste acontecimento além do sujeito que emitiu o enunciado, deflagrador do acontecimento, no caso a advogada, acusada de racismo, mais outros cinco sujeitos participam do processo de construção discursiva do acontecimento: os dois homens negros que fizeram a denúncia de racismo, duas testemunhas ouvidas no processo, os sujeitos posicionados na função de representantes da polícia judiciária, da promotoria e da magistratura.

Um aspecto de importância capital na análise do discurso foucaultiana é compreensão da materialidade, enquanto elemento constitutivo fundamental do enunciado. "O enunciado tem necessidade dessa materialidade; mas ela não lhe é dada em suplemento; uma vez estabelecida todas as determinações; em parte ela o constitui”. (FOUCAULT, 1987. p.105). Sendo assim, o enunciado que atribui a "todo preto" uma condição de inferioridade intelectual materializada na palavra "burro" e " estúpido" tem a sua espessura material delineada por uma estrutura social edificada no racismo, que, por sua vez, tem raízes fincadas no modo de produção escravista.

Esse enunciado se filia a uma memória construída sobre os negros escravizados, tidos como coisas, ou quando vistos enquanto humanos, avaliados como integrantes de uma raça desprovida de intelecto e que só servia para a realização de trabalhos manuais ou braçais. Portanto, o enunciado que afirma que todos os negros possuem inferioridade intelectual, que os faz incapazes até de pensar e por isso são burros, reativa a memória de outros enunciados, vinculados a discursos referentes à inferioridade intelectual e moral dos negros.

A posição, definida no âmbito das relações de poder, dos sujeitos envolvidos nesse acontecimento discursivo assegura aos representantes das três instituições do sistema de Justiça, envolvidas no caso (Policia Civil, Ministério Público e Poder Judiciário), um lugar estratégico e privilegiado, pois estes sujeitos são detentores do saber para deliberarem se o fato de uma pessoa afirmar que todos os pretos são iguais - 
todos apresentam um baixo nível de qualidade intelectual - configura uma prática racista.

Foucault (2002) define o procedimento judicial como prática discursiva vinculada as relações de saber-poder, e como detentores do "saber jurídico" e do poder para decidir, fundamentado na autoridade que lhes é conferida por esse saber, estes sujeitos, posicionados nas diversas funções existentes nas instituições do sistema de justiça, estão credenciados a emitirem enunciados, fadados a estabelecer qual a verdade a ser dita a respeito dos acontecimentos, relacionados ao campo jurídico.

No quadro a seguir são destacados alguns trechos extraídos dos documentos que integram os autos do processo:

Quadro 01 - Trechos dos documentos que integram os autos do processo

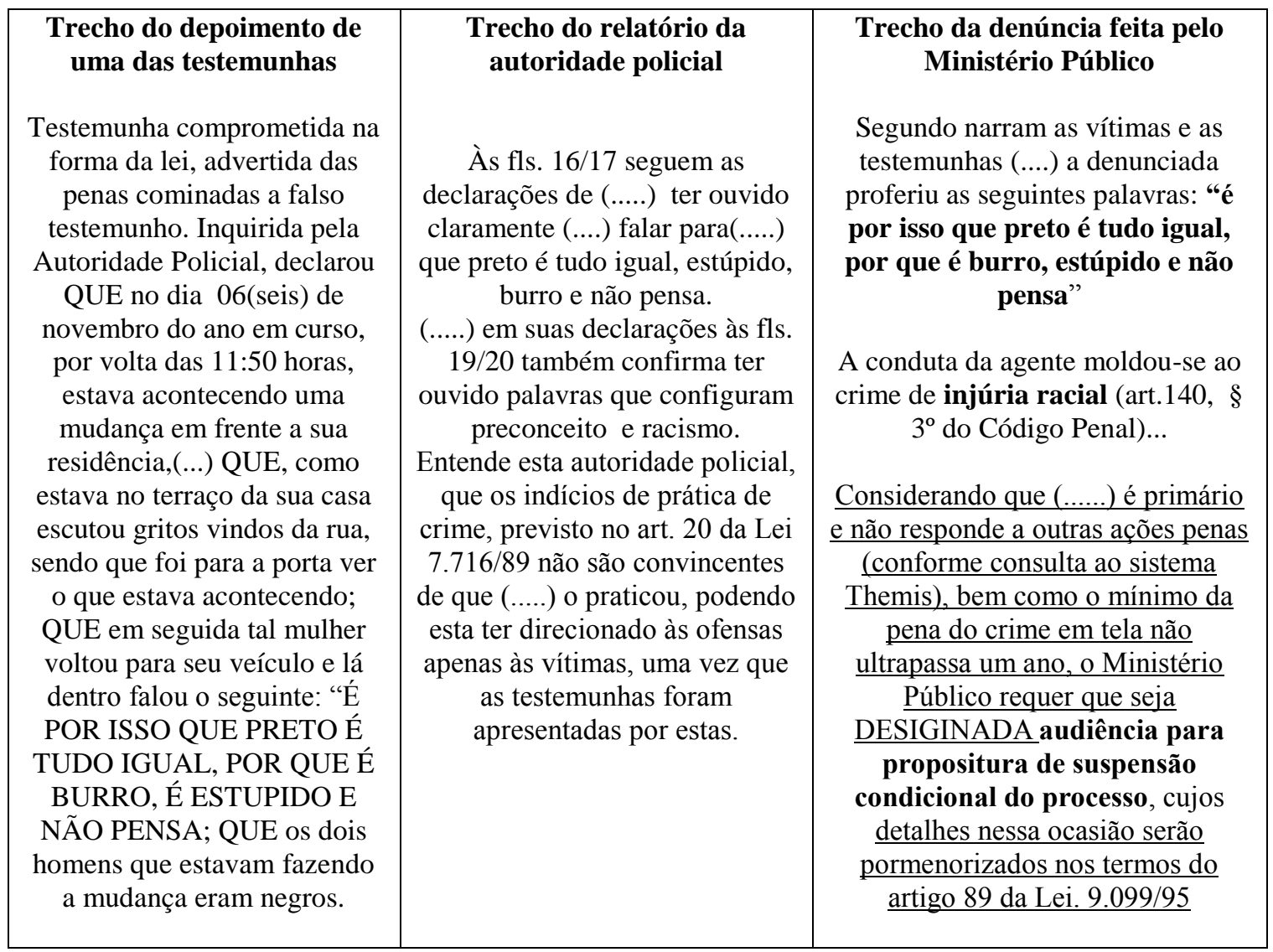

Fonte: Arquivo do Fórum de São Luís (MA). Processo n591682015

A autoridade policial afirma que não há nos autos elementos capazes de formar convicção de que a acusada incorreu em prática de racismo e sugere que a advogada teria dirigido ofensas somente às pessoas que a acusam de racismo, até pelo fato de que as duas testemunhas apresentadas para depor a respeito do ocorrido foram 
indicadas por estas pessoas. O parecer do Ministério Público seguiu nessa mesma convicção e afirma que a conduta da agente não indica a prática de racismo.

O método arqueogenealógico preconiza o caráter de historicidade que permeia todos os discursos, inclusive o discurso jurídico, cuja produção é condicionada por diversos procedimentos de controle e organização destinados a exercer a tarefa de "conjurar seus poderes e perigos, dominar seu acontecimento aleatório, esquivar sua pesada e temível materialidade". (FOUCAULT, 1996, p.8). Essa "terrível materialidade" diz respeito às regras que condicionam a emergência ou a submersão de qualquer discurso, inclusive os discursos jurídicos.

Este pressuposto implica reconsiderar o discurso que concebe o Direito e as instituições do sistema de justiça com as credenciais de um poder soberano, detentor de uma delegação emanada da coletividade que os coloca com o status de legitimados a produzir verdade. A esse respeito disso, Foucault (2005) pondera:

\begin{abstract}
Meu problema seria de certo modo este: quais são as regras de direito de que lançam mãos as relações de poder para produzir discursos de verdade? Ou ainda: qual é esse tipo de poder capaz de produzir discursos de verdade que são numa sociedade como a nossa, dotados de efeitos tão potentes?(....) Somos submetidos pelo poder à produção da verdade, só podemos exercer o poder mediante a produção da verdade. Isso é verdadeiro em toda sociedade, mas acho que na nossa essa relação entre poder, direito e verdade se organiza de um modo muito particular. (FOUCAULT, 2005, p. 28-29).
\end{abstract}

A análise desse acontecimento discursivo, sob o prisma do método arqueogeneleógico, possibilita identificar como o racismo estrutural atravessa as relações de poder de uma estrutura social, constituída pelo racismo, inclusive circulando nas instituições do Sistema de Justiça do Estado.

Nesse episódio, embora houvesse a clara manifestação de prática de racismo, prevista no artigo 20 da Lei 7.716/89, cujo comando normativo define entre as condutas tipificadas como práticas racistas: "Praticar, induzir ou incitar a discriminação ou preconceito de raça, cor, etnia, religião ou procedência nacional”, a verdade produzida nos autos tem sua gênese na emergência de um discurso de negação do racismo, que atravessa tanto as instituições do sistema de justiça, quanto os "saberes" produzidos pelos sujeitos integrantes destas instituições.

Conforme enfatiza Foucault (1997), é preciso compreender as práticas discursivas além da mera elaboração de discursos, pois elas são constituídas a partir de “conjuntos de técnicas, em instituições, em esquemas de comportamento, em tipos de 
transmissão em formas pedagógicas que ao mesmo tempo as impõem e às mantém". (FOUCAULT, 1997, p.12).

Neste momento, os integrantes das instituições do sistema de justiça, que também estão inseridos em relações de poder, inerentes a todos os acontecimentos discursivos, elaboram, por meio do saber jurídico, enunciados vinculados ao discurso de negação do racismo, que produz e ao mesmo tempo é produzido por relações de saber/poder, onde esse discurso se constitui e por onde circula.

No método arquegenealógico a compreensão do caráter fundante do discurso enfatiza sua importância capital enquanto elemento crucial na construção dos sujeitos, dos saberes e dos poderes Nesse aspecto, é importante destacar que o sujeito que emitiu os enunciados de ofensa era uma advogada e, portanto, alguém que ocupava uma posição considerada privilegiada, nas relações de poder. Destacamos ainda que houve manifestação de resistência ao exercício do poder que gerou enunciados racistas, e isto deslocou a situação para o campo jurídico, no qual surgiram enunciados também permeados por estratégias de saber e de poder.

Outro aspecto importante a ser ressaltado é que este acontecimento discursivo, ao se deslocar para o campo jurídico, ingressando na esfera das instituições do sistema de Justiça, foi catalogado como processo, mas não chega a trilhar um percurso que leve, por exemplo, ao julgamento do caso, nem mesmo em primeira instância.

Este acontecimento teve breve existência no âmbito das instituições do sistema de justiça, foi encerrado após o recebimento da denúncia, com a suspensão condicional do processo; posteriormente, foi dado o arquivamento do caso, após a acusada cumprir as condições necessárias para ter decretada a extinção da punibilidade. Isso indica a manifestação de um procedimento de controle dos discursos que Foucault (1996) define como interdição:

Sabe-se bem que não se tem o direito de dizer tudo, que não se pode falar de tudo em qualquer circunstância, que qualquer um, enfim, não pode falar de qualquer coisa. Tabu do objeto, ritual da circunstância, direito privilegiado ou exclusivo do sujeito que fala: temos aí o jogo de três tipos de interdições que se cruzam, se reforçam ou se compensam, formando uma grade complexa que não cessa de se modificar. (FOUCAULT, 1996, p.09 Grifo nosso.)

O não reconhecimento do crime de racismo no processo analisado se enquadra. portanto, na observação que Foucault faz sobre o tabu do objeto, na medida em que falar em racismo no Brasil é um tabu, ainda nos dias atuais. 


\section{Considerações Finais}

Neste artigo, propomos a análise da negação da existência do racismo, no Brasil, no âmbito das instituições do sistema de justiça do Maranhão. Nossa problemática situou-se na observação de que negar o racismo constitui uma prática que respalda a impunidade do crime de racismo.

Para a verificação da problemática analisamos um processo encontrado no site do sistema de Justiça do Maranhão e observamos, por meio do método de análise arqueogenealógico, que a negação do racismo no Brasil é uma prática discursiva que se filia a discursos de miscigenação, como o discurso da democracia racial. Esse discurso se infiltrou fortemente em práticas (não) discursivas da cultura brasileira, agindo como uma espécie de dispositivo.

A lei da injúria racial torna, no âmbito discursivo, o campo da justiça um dispositivo de disseminação de práticas de racismo. A circulação dos discursos do racismo estrutural, amplamente apoiados na negação do racismo, não se limita ao domínio das instituições do sistema de Justiça, mas encontra nessas instituições um espaço propício para atuar de forma incisiva.

\section{Referências}

ALMEIDA Sílvio Luiz de. O que é racismo estrutural? Belo Horizonte (MG): Letramento, 2018.

Democracia racial. Entrevista à TV Campus UFSM. Disponível em: https://www.youtube.com/watch?v=34hiFz_Pu2o. Acesso em: 23 de junho de 2020.

ARAÚJO. Vera Lúcia Santana. O desvio da injúria racial como suporte à intolerância no Brasil. Disponível em < https://www.conjur.com.br/2018-jun-19/veraaraujo-desvio-injuria-racial-suporte-intolerancia>. Acesso em 10 de junho de 2018

FOUCAULT, Michel. A Arqueologia do Saber. Rio de Janeiro: Forense, 2010.

. Ditos e escritos-Volume III. Rio de Janeiro: Editora Forense, 2005.

. A verdade e as formas jurídicas. Rio de Janeiro: Nau, 2002.

Resumo dos cursos do collège de France:(1970-1982). Zahar, 1997.

A ordem do discurso: aula inaugural no Collège de France, pronunciada em 2 de dezembro de 1970. Edições Loyola, 1996.

GONÇALVES, Sérgio Campos. O método arqueológico de análise discursiva: o percurso metodológico de Michel Foucault. Revista História e-história. Campinas (SP); Unicamp, p.1-21, 2009. Disponível em: https://www.researchgate.net/publication/216881614_O_metodo_arqueologico_de_anal 
ise discursiva_o_percurso_metodologico_de_Michel_Foucault Acesso em: 30 out. 2018.

GREGOLIN, Maria do Rosário Valencise. Língua(gens), mídia(s) e poder sob a ótica discursiva foucaultiana - Entrevista com Maria do Rosário Gregolin. Revista Heterotópica. Uberlândia: UFU, 2018. Disponível em: http://www.seer.ufu.br/index.php/RevistaHeterotopica/issue/archive. Acesso em: 20/04/2019.

MUCHAIL, Salma Tannus. Foucault, simplesmente. São Paulo: Edições Loyola, 2004.

SILVA JÚNIOR, Francisco Carlos da. Coisa de Preto e Norma de Branco: a circulação dos discursos do racismo estrutural nas Instituições do Sistema de Justiça do Maranhão (Policia Judiciária, Ministério Público e Poder Judiciário). Dissertação de mestrado apresentado no Programa de Pós-Graduação em Direito da Universidade Federal do Maranhão. São Luís: UFMA, 2019.

REVEL, Judith. Foucault: conceitos essenciais. Claraluz (São Carlos): 2006.

ROCHA, José Manuel de Sacadura. Michel Foucault e o Direito. Rio de Janeiro: Forense Universitária, 2011.

WESTIN, Ricardo. Negro continuará sendo oprimido enquanto o Brasil não se assumir racista, dizem especialistas. Informatéria. Portal Senado. Disponível em: https://www12.senado.leg.br/noticias/infomaterias/2020/06/negro-continuara-sendooprimido-enquanto-o-brasil-nao-se-assumir-racista-dizem-especialistas. Acesso em: 14 de junho de 2020. 